\title{
New Developments in the Treatment of Alzheimer's Disease
}

$\mathbf{T}$ his ACADEMIC HighLIGHTS section of The Journal of Clinical Psychiatry presents the highlights of the planning teleconference series "New Developments in the Treatment of Alzheimer's Disease," which was held June 2008. This report was prepared by the CME Institute of Physicians Postgraduate Press, Inc., and was supported by an educational grant from Forest Pharmaceuticals, Inc.

The planning teleconference series was chaired by Peter V. Rabins, MD, MPH, Department of Psychiatry and Behavioral Sciences, the Geriatric Psychiatry Program, and the Geriatric Psychiatry Mobile Treatment, Johns Hopkins Hospital, Baltimore, Md. The faculty were Neill GraffRadford, MB BCh, FRCP, Department of Neurology, Mayo College of Medicine and Mayo Clinic Hospital, Jacksonville, Fla; Gary W. Small, MD, Department of Psychiatry and Biobehavioral Sciences, David Geffen School of Medicine, and the UCLA Center on Aging, University of California, Los Angeles; and Roy Yaari, MD, MAS, Memory Disorders Center, Banner Alzheimer's Institute, Phoenix, Ariz.

Financial disclosure: Dr. Rabins is a member of the speakers bureau for Forest. Dr. Graff-Radford is a consultant for Johnson \& Johnson and has received grant/ research support from the National Institute on Aging, Myriad Genetics, Elan, and Pfizer; Dr. Small is a consultant for and/or has received lecture fees from Abbott, Dakim, Eisai, Forest, Mattel, Myriad Genetics, Novartis, Ortho-McNeil, Pfizer, Radica, Siemens, and VerusMed; has received stock options from Dakim; and is among the inventors of and receives royalties on U.S. patent no. 6,274,119, "Methods for Labeling Beta-Amyloid Plaques and Neurofibrillary Tangles," which was licensed to Siemens. Dr. Yaari is a consultant for Merck.

The opinions expressed herein are those of the faculty and do not necessarily reflect the views of the CME provider and publisher or the commercial supporter.

(c) Copyright 2009 Physicians Postgraduate Press, Inc.
First identified as a disease process in the early 1900s, today Alzheimer's disease (AD) looms as a public health crisis. In 2000, an estimated 4.5 million persons in the United States had mild, moderate, or severe $\mathrm{AD}$; this figure could grow to 13.2 million by 2050. ${ }^{1}$ Peter V. Rabins, MD, MPH, brought together a group of experts to discuss ways to better diagnose and more effectively treat this rapidly growing population.

\section{Progression From Mild Cognitive Impairment to Alzheimer's Disease}

\section{Prevalence}

As the population ages and survival rates increase for patients with $\mathrm{AD}$, not only will the number of persons with the disease increase rapidly, said Neill Graff-Radford, MB BCh, FRCP, but also the age distribution of persons with AD will change. In 2000, the majority of persons with $\mathrm{AD}$ were between the ages of 75 and 84 years; by 2050, persons with $\mathrm{AD}$ in this age group could double from 2.4 million to 4.8 million. ${ }^{1}$ However, the number of individuals with $\mathrm{AD}$ who are aged 85 years or older is expected to more than quadruple, from 1.8 million to 8 million. ${ }^{1}$

The prevalence of AD increases with age, and the proportion of patients with severe AD as opposed to mild or moderate AD also increases with age. In 2000, AD was present in about $5 \%$ of those aged 65 to 74 years, almost $20 \%$ of those aged 75 to 84 years, and more than $45 \%$ of those aged 85 years or older. ${ }^{1}$

Autopsies have shown that AD is by far the most common type of dementia in the elderly, playing a role in $77 \%$, observed Dr. Graff-Radford. ${ }^{2}$ The next most common form of dementia is Lewy body disease (26\%), followed by vascular dementia (18\%), hippocampal sclerosis (13\%), and frontotemporal dementia (5\%). Barker et $\mathrm{al}^{2}$ found that concomitant $\mathrm{AD}$ was present in the majority of patients with vascular dementia, Lewy body disease, and hippocampal sclerosis.

\section{Pathology}

A pathological hallmark of $\mathrm{AD}$ is senile amyloid plaques in the brain, which are created through the deposition of amyloid beta $(A \beta)$, specifically the insoluble $A \beta_{42}$ species of protein, leading to accumulations of $A \beta$ deposits. $^{3}$

Persons with the apolipoprotein E4 genotype (ApoE4) have greater amyloid deposits in the brain ${ }^{4}$ and are universally accepted to be at greater risk for AD, said Dr. Graff-Radford. One study ${ }^{5}$ found that people with homozygote ApoE4 alleles had a 55\% chance of $\mathrm{AD}$ if they lived to 85 , those with 1 allele had a $27 \%$ chance, and those without ApoE4 had a 9\% chance.

Another pathological characteristic of $\mathrm{AD}$ is neurofibrillary tangles (NFTs), which are aggregates of abnormally hyperphosphorylated tau proteins. The NFT burden has been correlated more closely with the severity of clinical symptoms in AD than the extent of amyloid load. ${ }^{6}$

A study ${ }^{7}$ of 392 twin pairs in which 1 or both twins had AD evaluated the relative importance of genetic and environmental influences on $\mathrm{AD}$. The researchers calculated that, after controlling for age, the heritability of AD was 


\section{For Clinical Use}

- Alzheimer's disease (AD) is an already prevalent diagnosis that is predicted to increase rapidly in the next few decades.

- New diagnostic tests and neuroimaging techniques are helping to diagnose AD earlier and more accurately.

- Treatments approved for $\mathrm{AD}$ include cholinesterase inhibitors and an $N$-methyl-D-aspartate antagonist, and new drugs are in development using a variety of potential treatment targets.

between $58 \%$ and $79 \%$. Genetic factors were similar for men and women. Thus, prevalence and heritability data indicate that age and genetics are the crucial risk factors for $\mathrm{AD}$, said Dr. Graff-Radford.

\section{Mild Cognitive Impairment}

Mild cognitive impairment (MCI) is the pathological condition that lies along a continuum between the cognitive changes seen in the normal aging process and early dementia. A set of criteria for diagnosing MCI has been developed. ${ }^{8}$ The first criterion is a subjective cognitive complaint from the patient, preferably corroborated by an informant. Second, neuropsychological testing should confirm that the patient has cognitive impairment relative to his or her age. Third, despite cognitive problems, the patient's general in- tellectual functioning should be near normal. The last criterion is that the patient is able to function normally. Based on these criteria and the Diagnostic and Statistical Manual of Mental Disorders ${ }^{9}$ definition of dementia, the physician may conclude that the patient does not meet the criteria for dementia.

Subtypes of MCI have been identified (Figure 1). ${ }^{8,10}$ If memory impairment is the main cognitive problem, the patient is considered to have amnestic MCI. Nonamnestic MCI could mean the patient's main cognitive problem is with language, visuospatial skills, executive function, or attention. If only 1 cognitive domain is affected (whether it is memory or not), then the person has single domain MCI. If the person has several areas of cognitive impairment, he or she is considered to have multiple domain MCI. ${ }^{8}$

The MCI subtypes may have different etiologies, which can help to determine the eventual outcome for the patient (Figure 2). ${ }^{10}$ For example, for amnestic MCI, etiologies include AD, vascular cognitive impairment, or depression, and, for nonamnestic MCI, the etiology may be frontotemporal dementia, Lewy body dementia, or vascular cognitive impairment.

In a population-based study of 1,704 individuals with a median age of 79 years, the prevalence rate of MCI was $17 \% .{ }^{11}$ Among those 70 to 74 years, 9\% had MCI, and among those 85 to 89 years, $25 \%$ had MCI. Three fourths had amnestic MCI. More men than women had MCI, and the rate was also higher in people with fewer years of education.

Figure 1. Flowchart for Diagnosis of Mild Cognitive Impairment (MCI) Subtypes ${ }^{\mathrm{a}}$

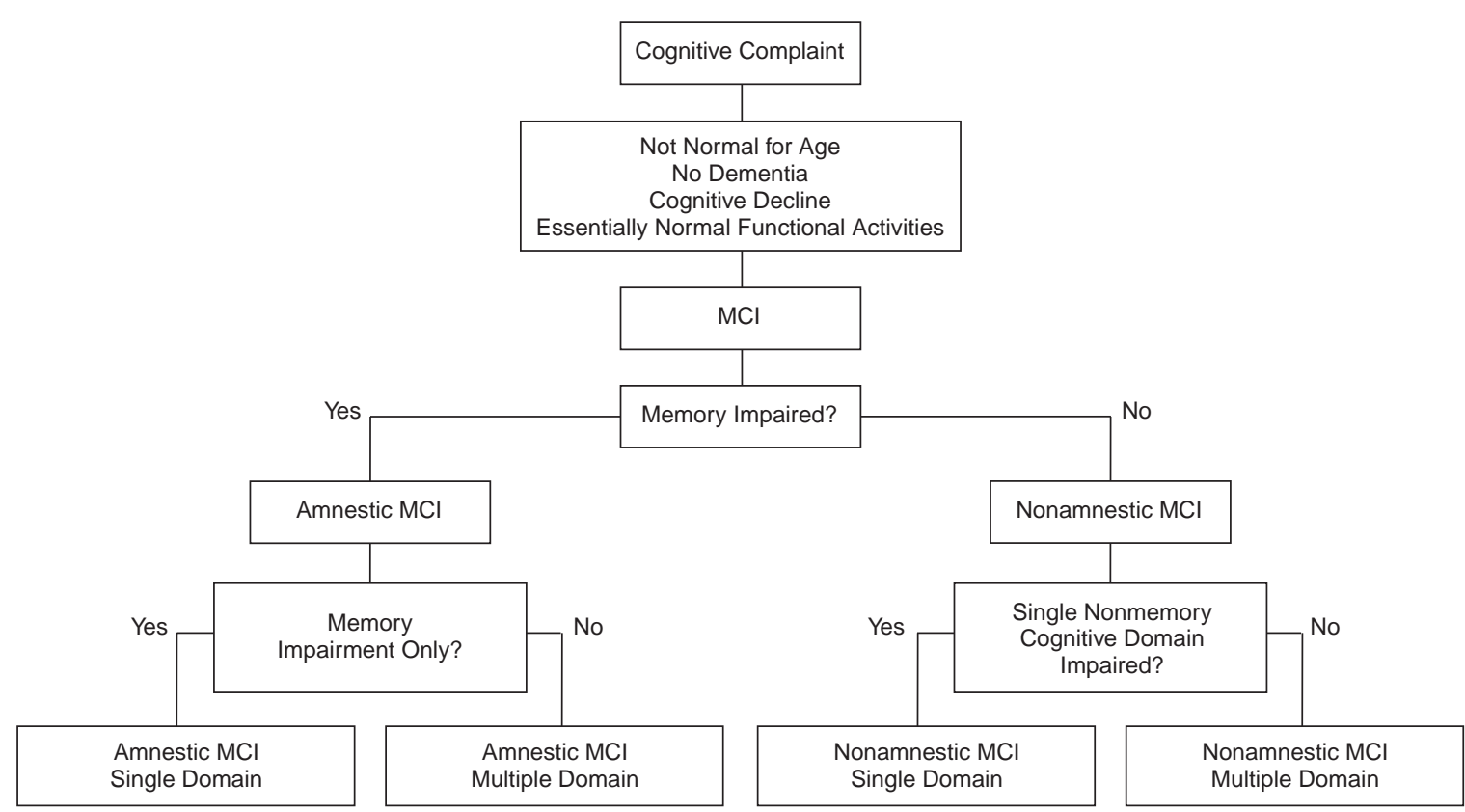

${ }^{a}$ Reprinted with permission from Petersen and Morris. ${ }^{10}$ 


\section{Figure 2. Combining MCI Subtypes With Presumed Etiology ${ }^{\mathrm{a}}$}

\begin{tabular}{|c|c|c|c|c|c|c|}
\hline \multirow{6}{*}{ 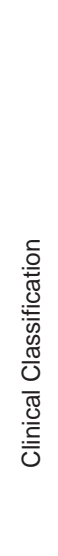 } & & & \multicolumn{4}{|c|}{ Etiology } \\
\hline & \multirow{3}{*}{$\begin{array}{c}\text { Amnestic } \\
\mathrm{MCl}\end{array}$} & \multirow[b]{2}{*}{$\begin{array}{l}\text { Single } \\
\text { Domain }\end{array}$} & \multirow{2}{*}{$\begin{array}{c}\text { Degenerative } \\
\text { AD }\end{array}$} & \multirow[t]{2}{*}{ Vascular } & \multirow{2}{*}{$\begin{array}{c}\text { Psychiatric } \\
\text { Depr }\end{array}$} & $\begin{array}{c}\text { Medical } \\
\text { Conditions }\end{array}$ \\
\hline & & & & & & \\
\hline & & $\begin{array}{l}\text { Multiple } \\
\text { Domain }\end{array}$ & $A D$ & $\mathrm{VaD}$ & Depr & \\
\hline & \multirow{2}{*}{$\begin{array}{c}\text { Nonamnestic } \\
\mathrm{MCl}\end{array}$} & $\begin{array}{l}\text { Single } \\
\text { Domain }\end{array}$ & FTD & & & \\
\hline & & $\begin{array}{l}\text { Multiple } \\
\text { Domain }\end{array}$ & DLB & $\mathrm{VaD}$ & & \\
\hline $\begin{array}{l}\text { Repr } \\
\text { Abbr } \\
\text { bodie } \\
\text { VaD }\end{array}$ & $\begin{array}{l}\text { ted with perm } \\
\text { iations: } A D= \\
\text { FTD = fronto } \\
\text { vascular deme }\end{array}$ & $\begin{array}{l}\text { sion fror } \\
\text { Alzheime } \\
\text { emporal } \\
\text { tia. }\end{array}$ & $\begin{array}{l}\text { Petersen and } \\
\text { s disease, Dep } \\
\text { mentia, } \mathrm{MCI}=\end{array}$ & $\begin{array}{l}\text { orris. }^{10} \\
=\text { depressio } \\
\text { nild cognit }\end{array}$ & $\begin{array}{l}\text { LB = demen } \\
\text { impairment, }\end{array}$ & a with Lewy \\
\hline
\end{tabular}

Petersen et $\mathrm{al}^{12}$ studied patients with MCI and healthy control subjects. During 4 years of follow-up, $12 \%$ of patients diagnosed with $\mathrm{MCI}$ at baseline converted to AD each year. During 10 years of follow-up, healthy control subjects developed MCI or AD at a rate of $1 \%$ to $2 \%$ per year. Identifying MCI in a patient could be useful as a predictor for $\mathrm{AD}$ and allow for earlier intervention in the disease process.

\section{Cerebrospinal Fluid Biomarkers for AD in MCI Patients}

One way to predict whether MCI will progress to $\mathrm{AD}$ is to study biomarkers in the patient's cerebrospinal fluid (CSF). Riemenschneider et $\mathrm{al}^{13}$ found that patients with MCI who progressed to probable $\mathrm{AD}$ had higher CSF tau protein levels and lower $A \beta_{42}$ protein levels than patients with stable MCI. Dr. Graff-Radford added that patients with MCI in Europe often undergo a spinal tap to determine their tau and $\mathrm{A} \beta_{42}$ levels, while patients with MCI in the United States are more commonly followed clinically.

Fagan et $\mathrm{al}^{14}$ found that, whether individuals had dementia or not, the level of CSF $A \beta_{42}$ corresponded with the presence or absence of amyloid de- posits in the brain. Together, the presence of brain amyloid deposits (determined by imaging tests) and reduced levels of CSF A $\beta_{42}$ can help to confirm the clinical diagnosis of MCI related to AD pathology and can also possibly be used to predict future MCI in cognitively normal individuals or progression to $\mathrm{AD}$ in people with MCI.

\section{Plasma Biomarkers for AD in MCI Patients}

Using the comparison of checking cholesterol levels to predict heart disease, Dr. Graff-Radford reported on a
Accurately diagnosing AD in clinical practice remains challenging. Gary W. Small, MD, cited a literature review ${ }^{19}$ of studies that addressed the diagnostic accuracy of current sets of criteria. Criteria for dementia of the Alzheimer's type in the Diagnostic and Statistical Manual of Mental Disorders, Third Edition, and criteria for probable AD from the National Institute of Neurological and Communicative Disorders and $\mathrm{AD}$ and Related study ${ }^{15}$ that he and his colleagues conducted to investigate whether plasma levels of $A \beta_{40}$ and $A \beta_{42}$ could identify cognitively normal persons at risk for MCI or AD. The study found that participants with plasma ratios of $A \beta_{42}$ / $\mathrm{A} \beta_{40}$ in the lowest quartile had 3 times the risk for developing MCI or $\mathrm{AD}$ compared to those in the highest quartile. These findings were similar to those reported by van Oijen et al. ${ }^{16}$ They found that those in the lowest tertile of the $A \beta_{42} / A \beta_{40}$ ratio had a 10 times greater chance of developing dementia. Another study ${ }^{17}$ has shown that the same low plasma ratio of $\mathrm{A} \beta_{42} /$ $\mathrm{A} \beta_{40}$ in subjects with depression was associated with greater impairment in memory, possibly representing a subtype of depression that could be a manifestation of prodromal AD.

Searching for a molecular test for AD, Ray et al $^{18}$ identified 18 signaling proteins found in blood plasma that could distinguish normal controls from individuals with $\mathrm{AD}$ with almost $90 \%$ accuracy. These blood proteins also correctly predicted those individuals with MCI who would later develop AD.

\section{Conclusion}

The prevalence of $\mathrm{AD}$ is growing as the population ages. An understanding of the biomarkers that predict risk for developing AD, concluded Dr. GraffRadford, may enable studies of how to delay or prevent the disease.

\section{Advances in Neuroimaging and Other Diagnostic Strategies}

Disorders Association averaged a good sensitivity of $81 \%$, with $70 \%$ specificity. Criteria for a "possible" AD diagnosis had a high sensitivity of $93 \%$, with $48 \%$ specificity. With fairly low specificity, room for improvement exists, said Dr. Small.

Use of imaging tools can increase the diagnostic accuracy of AD. The Alzheimer's Disease Neuroimaging Initiative $^{20}$ now provides information to clinicians on which neuroimaging 
Table 1. Correlations Between Neuropsychological Performance and Quantitative MRI Analysis of Neuropsychological Domains ${ }^{\mathrm{a}}$

\begin{tabular}{|lccc|}
\hline Neuropsychological Domain & VBR & Hippocampal Volume & Temporal Horn Volume \\
\hline Immediate memory & $-.27^{*} *$ & $.22^{*}$ & $-.28 \dagger$ \\
Delayed memory & $-.24^{*}$ & $.26^{* *}$ & $-.22^{*}$ \\
Visual/spatial/praxis & $-.19^{*}$ & .03 & $-.19^{*}$ \\
Language & $-.32 \dagger$ & .06 & $-.39 \dagger$ \\
Executive & $-.26^{* *}$ & -.03 & $-.19^{*}$ \\
Intelligence & $-.21^{*}$ & $.21^{*}$ & -.11 \\
\hline${ }^{2}$ Reprinted with permission from Bigler et al. ${ }^{30}$ & & \\
${ }^{*} P=.05$. & & \\
$* * P=.01$. & \\
$\dagger$ Significant after Bonferroni correction, $P=.008$. & \\
Abbreviation: VBR = ventricle-to-brain ratio. & \\
\hline
\end{tabular}

tools are the most helpful in diagnosing and monitoring $\mathrm{AD}$ and the effects of $\mathrm{AD}$ treatments.

\section{Structural Imaging Tools}

In clinical practice today, magnetic resonance imaging (MRI) and computed tomography scans are used to rule out space-occupying lesions, tumors, strokes, normal pressure hydrocephalous, and so forth, said Dr. Small. However, these structural imaging tools can also be used to detect tissue atrophy to rule in a diagnosis of $\mathrm{AD}$.

Generally, atrophy in the medial temporal regions is greater in patients with AD compared with controls. Frisoni et $\mathrm{al}^{21}$ demonstrated that highresolution MRI can pinpoint in vivo the regions and subregions that are informative about diagnosis. Their imaging of patients with mild-tomoderate $\mathrm{AD}$ showed tissue loss of $20 \%$ or more in the hippocampal formation. Another study ${ }^{22}$ using MRI has shown that patients with AD had $10 \%$ to $15 \%$ greater cortical atrophy than patients with amnestic MCI, making MRI a useful technique for differentiating these 2 groups during diagnosis.

\section{Functional Imaging Tools}

Different types of imaging can assist clinicians with prognosis. Functional imaging tools, such as positron emission tomography (PET), can be used to predict disease progression. Metabolism throughout the cortex and deeper structures can be progressive or nonprogressive, ${ }^{23}$ and $\mathrm{AD}$ has a recog- nizable pattern of progressive hypometabolism in the temporoparietal and posterior cingulate cortices. Other progressive diseases are associated with hypometabolism in other areas of the brain. Nonprogressive patterns of metabolism may be seen with a tumor or stroke. The use of PET to view areas of hypometabolism in the brain was studied as an adjunct in the diagnosis of $\mathrm{AD}$ and was found to increase diagnostic accuracy by decreasing false positive and false negative diagnoses. ${ }^{24}$

Mosconi et $\mathrm{al}^{25}$ combined PET with screening for the ApoE4 genotype to improve prediction of MCI conversion to AD. They found that hypometabolism in the inferior parietal cortex predicted conversion to AD with an accuracy of $84 \%$. In patients with the ApoE4 genotype, metabolism reductions within frontal areas such as the anterior cingulate and inferior frontal cortices increased prediction of conversion to AD to $94 \%$ accuracy.

Dr. Small also described a study ${ }^{26}$ that he and his colleagues conducted using PET in patients with normal memory to determine patterns of cognitive and metabolic decline. After 2 years, patients with one copy of the ApoE4 allele had 5\% lower inferior parietal and lateral temporal metabolism and 4\% lower left posterior cingulate metabolism. Amyloid senile plaques and tau NFTs are the neuropathological hallmarks of AD; they accumulate in cortical regions of the brain in people with MCI who are at risk for AD. Identifying the patterns of plaques and tangles in vivo can facili- tate early diagnosis. Small-molecule probes used with PET imaging in humans have shown differences in the areas of the brain known to collect plaques and tangles between patients with AD, those with cognitive impairment, and controls who are aging normally. ${ }^{27-29}$ As patients decline clinically, the plaque and tangle burden increases.

\section{Neuropsychological Testing}

Neuropsychological testing is often used to validate the diagnosis of $\mathrm{AD}$ and help differentiate MCI from AD and normal aging. A variety of cognitive functions on neuropsychological tests, such as immediate memory, have been found to correlate with various neuroimaging results, such as hippocampal volume measured by MRI, explained Dr. Small (Table 1). ${ }^{30}$

In clinical practice, these tests can be used to document and confirm cognitive deficits early in the disease or in atypical populations. Documenting specific deficits can assist in characterizing a specific dementia diagnosis and in determining the functional consequences of that diagnosis.

Neuropsychological tests can also be used to document disease progression; the rate of change in cognitive performance may predict a diagnosis up to a decade in advance. ${ }^{31}$ Computerized cognitive testing has been developed, which can improve the efficiency of testing in clinical practice; these tests can identify MCI or dementia even in patients with depression. ${ }^{32}$ Thus, neuropsychological tests can be used quantitatively and longitudinally.

\section{Conclusion}

Dr. Small ended by stating that neuroimaging increases the accuracy of clinical diagnosis in AD in several ways. Structural imaging can show hippocampal atrophy, which is accelerated in individuals with MCI and AD compared with controls. Functional imaging can reveal a characteristic pattern of parietal, temporal, and posterior cingulate hypometabolism in patients with AD. The ApoE4 allele 
further helps predict cognitive decline. Small-molecule probes hold tremendous promise in visualizing amyloid plaques and NFTs. In addition, neuropsychological testing continues to be helpful in the diagnosis of $\mathrm{AD}$ and allows for monitoring of disease progression and documentation of deficits.

\section{Current Treatments for Different Phases}

The American Psychiatric Association (APA) guidelines for the treatment of AD were first published in 1997 and

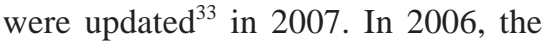
American Association of Geriatric Psychiatry (AAGP) published a position statement on principles of care for patients with $\mathrm{AD},{ }^{34}$ and in 2001 , the American Academy of Neurology (AAN) published its practice parameter for managing dementia. ${ }^{35} \mathrm{Dr}$. Rabins reviewed and compared these guidelines for the treatment of AD.

\section{American Psychiatric Association}

The APA guidelines ${ }^{33}$ advise that the treatment of patients with AD should be based on the results of a thorough evaluation of their medical, neurological, and psychiatric status. Medical problems that may contribute to dementia should be identified and treated.

The APA states that cholinesterase inhibitors (ie, tacrine, donepezil, rivastigmine, and galantamine) are modestly effective for treating AD symptoms. These agents and memantine, an
$N$-methyl-D-aspartate (NMDA) antagonist, have been approved by the US Food and Drug Administration (FDA) for the treatment of different phases of AD (Table 2). ${ }^{36}$

Vitamin $\mathrm{E}$ is no longer recommended for AD by the APA. Highdose vitamin E may have cardiovascular toxicity, and trials have not supported efficacy in more than a decade. The guidelines also recommend against the use of estrogen or other hormone replacement therapy agents and against the use of nonsteroidal anti-inflammatory drugs (NSAIDs), based on both the potential for toxicity and adverse effects as well as a lack of demonstrated efficacy of either prevention or benefit once the diagnosis has been established. Evidence also does not currently support the use of ginkgo biloba, selegiline, or chelating agents.

The APA guidelines state that patients should be evaluated for major depression and treated with antidepressants if necessary. Pharmacotherapy for depression is beneficial in the AD population.

The use of antipsychotic agents should be limited. Evidence has shown that both first- and second-generation antipsychotics increase mortality risk for elderly patients. Therefore, it is recommended that nonpharmacologic interventions be tried first for disorders of behavior involving agitation, aggression, or symptoms of psychosis unless there is clear, acute danger or the symptoms are causing severe distress to the patient. Antipsychotics should be used only if they are necessary and effective. If, after an adequate

Table 2. Treatment Options for Alzheimer's Disease ${ }^{a}$

\begin{tabular}{|c|c|c|}
\hline Approved Indication & Description & Drug \\
\hline $\begin{array}{l}\text { Mild to moderate dementia } \\
\text { of the Alzheimer's type }\end{array}$ & Reversible ChEI & Tacrine \\
\hline $\begin{array}{l}\text { Mild to severe dementia } \\
\text { of the Alzheimer's type }\end{array}$ & Reversible, selective ChEI & Donepezil \\
\hline $\begin{array}{l}\text { Mild to moderate dementia } \\
\text { of the Alzheimer's type }\end{array}$ & Reversible ChEI & Rivastigmine \\
\hline Mild to moderate dementia & Reversible, competitive ChEI & Galantamine \\
\hline $\begin{array}{l}\text { Moderate to severe dementia } \\
\text { of the Alzheimer's type }\end{array}$ & Noncompetitive NMDA receptor antagonist & Memantine \\
\hline
\end{tabular}

trial, the agent shows no benefit, it should be discontinued; if the drug does provide benefit, its use should be reassessed after several months and a dosage reduction trial considered.

Although stating that not enough rigorous evaluation has been done on the efficacy of psychosocial treatments, the APA guidelines advise that some research does support its effectiveness. Dr. Rabins added that caregiver education and support improve the emotional well-being of the caregiver and also decrease behavioral and neuropsychiatric symptoms in the patient.

\section{American Association for Geriatric Psychiatry}

The AAGP position statement on principles of care for patients with $A D$ stresses that the management of vascular disease and its risk factors should be considered a part of the standard care for these patients. ${ }^{34}$ Care should include monitoring the patient's blood pressure, glucose, cholesterol, and homocysteine levels. The administration of low-dose aspirin or other anticoagulation treatment should be considered for patients who have significant vascular disease.

The AAGP supports the use of cholinesterase inhibitors in the treatment of mild to moderate AD but recommends that tacrine be avoided due to its complex titration and risk of hepatic toxicity. The position statement cites better evidence for the combination of memantine with a cholinesterase inhibitor than for switching between cholinesterase inhibitors or combining 2 of them.

Dr. Rabins pointed out that the AAGP principles of care caution against doses of vitamin $\mathrm{E}$ above 400 IU per day. The AAGP also does not recommend using estrogen, ginkgo biloba, or NSAIDs as treatments for AD.

The AAGP guidelines give similar recommendations concerning antipsychotics as the APA. The AAGP policy statement also emphasizes caregiver support and education about patient 
safety and health, problem-solving skills, long-term care planning, and respite for oneself.

\section{American Academy of Neurology}

Because the AAN practice parameter is an older set of guidelines than the others, it not only supports the use of cholinesterase inhibitor medications for AD but also reports efficacy of vitamin $\mathrm{E}$ and requests more study of selegiline, NSAIDS, and estrogen. ${ }^{35}$ Recommendations regarding antipsychotic medicines and antidepressants in patients with AD are similar to those of the other 2 sets of guidelines. Caregiver education is also recommended to delay the time to nursing home placement.

\section{Conclusion}

The APA guidelines, the AAGP principles of care, and the AAN practice parameter agree on many elements of treating patients with AD. Various medications are approved for the treatment of different phases of $\mathrm{AD}$, but nonpharmacologic interventions for both patients and caregivers are also crucial. Dr. Rabins reminded clinicians that recommendations will change as new treatments and diagnostic tests become available for AD.

\section{Advances in \\ Pharmacotherapy and Potential New Treatment Targets}

Treatments in development for AD are currently divided into the 2 major categories of symptomatic therapy and disease-modifying therapy. Symptomatic therapies do not affect the underlying pathological process of $\mathrm{AD}$ that leads to cell death, but they can provide benefit for the patient in such areas as cognition, global measures, activities of daily living, and behavior. Disease-modifying therapies are drugs that target the pathophysiology of AD and could potentially slow or stop disease progression. ${ }^{37}$ The earlier that this type of therapy could be used in the disease process, the greater benefit it could provide to the patient. These categories are not mutually exclusive; potentially, a compound could be both a symptomatic therapy and a diseasemodifying therapy.

Both symptomatic and diseasemodifying therapies are under investigation (Table 3). Investigational symptomatic therapies are mainly neurotransmitter-based interventions. Disease-modifying therapies target either the amyloid pathway or the tau pathway. Roy Yaari, MD, MAS, reviewed current research into new treatments for $\mathrm{AD}$.

\section{Symptomatic Treatments}

Cholinergic therapies. The cholinergic hypothesis is based on considerable evidence that central cholinergic neurotransmission plays a critical role in aspects of cognition. ${ }^{38}$ The production of choline acetyltransferase, a key enzyme in the synthesis of the neurotransmitter acetylcholine, is reduced in $\mathrm{AD}$, which leads to less acetylcholine synthesis and, therefore, impaired cortical cholinergic function. ${ }^{39}$

The hypothesis that the amelioration of cholinergic neurotransmission would result in improved cognition led to the development of the acetylcholinesterase inhibitors. These drugs inhibit the cholinesterase enzyme from breaking down acetylcholine, increasing both the level and the duration of action of acetylcholine. New cholinesterase inhibitors are in development.

Additionally, research has shown that nicotinic acetylcholine receptors are lost in the hippocampus and temporal and frontal cortex in patients with $\mathrm{AD}^{40}$ In small studies, nicotine improved memory, cognition, and attention in $\mathrm{AD}$, while nicotinic antagonists showed the opposite effect. ${ }^{41}$ Nicotinic agonists that selectively target the central nervous system (CNS) are in development. $^{40}$

Glutamatergic therapies. Glutamate is the primary excitatory amino acid in cortical and hippocampal neurons, and it plays an important role in synaptic transmission. ${ }^{42}$ Normally, it binds to a variety of receptors, resulting in long-term potentiation of neuronal activity that may be critical in memory and learning. Excessive activation of these receptors by glutamate can destroy cells through what is called excitotoxicity, ${ }^{43}$ so it is possible that glutamatergic dysregulation plays a role in AD. The NMDA receptors are a subtype of glutamate ionotropic receptors, and NMDA receptor antagonists are in development; memantine is the only one approved at this time.

Histamine modulators. Histamine, a neurotransmitter in the brain, may play a role in the control of cognition and is decreased in the brains of patients with AD. ${ }^{44}$ Therefore, drugs that increase histaminergic activity may improve cognition in AD. Preclinical tests of $\mathrm{H} 3$ receptor antagonists have found improvement in attention and memory tasks, while $\mathrm{H} 3$ receptor agonists have had impairing effects on cognition. ${ }^{45}$

One particular histamine modulator, the antihistamine dimebon (dimebolin hydrochloride), is currently in phase III development. A 6-month randomized, double-blind, placebo-controlled phase II trial showed significant benefit of dimebon over placebo $(P<.0001)$ on cognitive measures in patients with mild to moderate $\mathrm{AD}$ (Figure 3) ${ }^{46}$ This compound is thought to inhibit neuronal death by mitochondrial-mediated inhibition of apoptosis ${ }^{47}$ and to contain properties that inhibit acetylcholine esterases and NMDA receptors. ${ }^{48}$

\section{Disease-Modifying Treatments \\ Amyloid-based interventions. Dr.} Yaari explained that the amyloid cascade hypothesis posits that one cause of $\mathrm{AD}$, as mentioned by Dr. Graff-Radford, is the accumulation, or decreased clearance, of $A \beta$ from the brain. The aggregation of $A \beta_{42}$ peptides into amyloid plaques is thought to interfere with cognition and lead to synaptic dysfunction and cell death and to contribute to the formulation of NFTs. Steps in this cascade could 


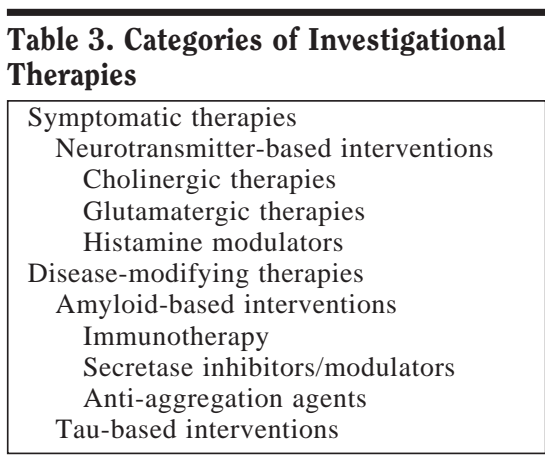

provide targets for drug development, which Dr. Yaari described (Figure 4). ${ }^{49}$

Immunotherapies. Immunotherapy could target several steps in the amyloid cascade hypothesis (see Figure 4). One immunotherapy hypothesis is that immunization could clear $A \beta$ from the brain through microglial-mediated phagocytosis. 50 The "sink" hypothesis of immunotherapy holds that brain plaque clearance does not require antibody entry into the brain or a cellmediated response but that brain $\mathrm{A} \beta$ can be reduced through an agent that sequesters plasma $A \beta$ peripherally into a "sink." 51

Immunotherapies can be divided into 2 categories: active and passive. ${ }^{49}$ Active immunotherapies introduce an antigen, which is a variant of the $\mathrm{A} \beta$ peptide, producing an immune response against that antigen. Passive immunization delivers synthetic antibodies against the $A \beta$ peptide into the host, facilitating an immune-mediated clearance of the antigen.

Passive immunotherapy requires less time to generate an immune reaction in the host than active immunization and also eliminates the issue of inadequate antibody response that is sometimes seen with active immunotherapy, especially in older people. However, active immunization could theoretically require a 1- or 2-time dose, whereas passive immunization would require regular administration of antibodies at fixed intervals to continue the immune response, said Dr. Yaari.

In transgenic mouse models of AD, immunotherapy has successfully

Figure 3. Effect of Dimebon on Cognition in Patients With Alzheimer's Disease ${ }^{\mathrm{a}}$

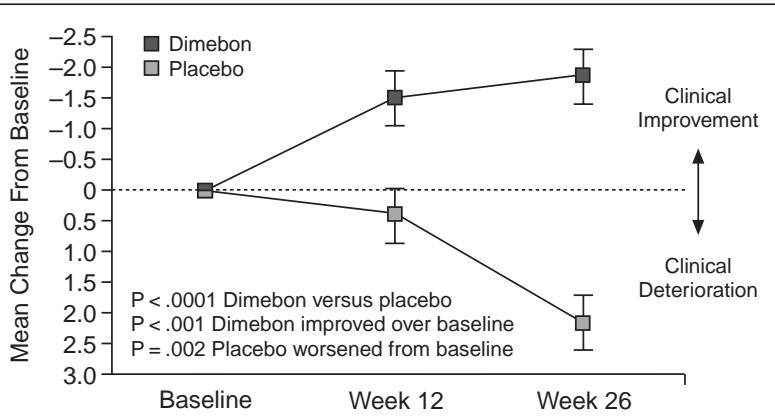

${ }^{a}$ Reprinted with permission from Doody et al.

Mean change in the ADAS-cog scale from baseline to week 26. All analyses shown are intention to treat, last observation carried forward analyses. Error bars show SE. P values are shown for comparison of mean changes from baseline for dimebon versus placebo groups at week 26, for dimebon mean baseline score versus week 26 mean score, and placebo mean baseline score versus week 26 mean baseline score.

Abbreviation: ADAS-cog = Alzheimer's disease assessment scale-cognitive subscale.

cleared $A \beta$ deposits ${ }^{52}$ and improved various cognitive deficits. ${ }^{53}$ In a human study ${ }^{54}$ using an active vaccine, 300 participants received the drug, and $59(19.7 \%)$ developed an antibody response; however, no clinical benefit was seen on the primary outcome measures. Those who responded to the antibody showed a decrease in CSF tau. Serial MRIs showed an unexpected loss of brain volume in the individuals who were antibody responders versus the placebo patients, but the decreased brain volume was not associated with worsened cognitive performance. ${ }^{55}$ Autopsies of patients who had responded to immunization showed clearance of amyloid plaque. $^{56}$

The study was prematurely terminated because $18(6 \%)$ of the participants developed aseptic meningoencephalitis. ${ }^{54}$ Current development efforts for active immunotherapies are focusing on activating highly specific antibody responses to the $\mathrm{A} \beta$ antigen to minimize adverse effects.

Passive immunotherapy trials are also underway. ${ }^{57}$ Bapineuzumab, a monoclonal antibody targeting amyloid, completed a phase II study showing benefit in a subgroup of patients. ${ }^{58}$ A very large phase III study of bapineuzumab is currently underway. Human intravenous immunoglobulin, a drug that is currently available for treatment of other neurological disorders and contains $A \beta$ antibodies, has shown positive effects in open-label pilot studies, such as reducing $A \beta$ in the CSF and stabilizing cognitive measures. ${ }^{59,60}$

Secretase inhibitors. The transmembrane amyloid precursor protein (APP) is a substrate for the 3 enzymes $\alpha$-, $\gamma$-, and $\beta$-secretase. Normally, APP is cleaved by $\alpha$-secretase at a site that does not result in $A \beta_{42}$ production, but, in pathological conditions, APP is cleaved initially by $\beta$-secretase and then $\gamma$-secretase, resulting in increased $\mathrm{A} \beta_{42}$ production (see Figure 4 ).

The $\beta$-secretase inhibitors are potentially more useful for AD than $\gamma$-secretase inhibitors because $\beta$ secretase inhibitors target one of the initial events in the amyloid cascade, but they tend to be large molecules, making it difficult to penetrate the blood-brain barrier. No $\beta$-secretase inhibitors have lasted beyond early clinical development.

The development of $\gamma$-secretase inhibitors is further along than that of $\beta$-secretase inhibitors. However, $\gamma$ secretase inhibitors also affect the Notch signaling protein, which is an important intermediary in cellular functions that regulate the differentiation of cells in such areas as the 


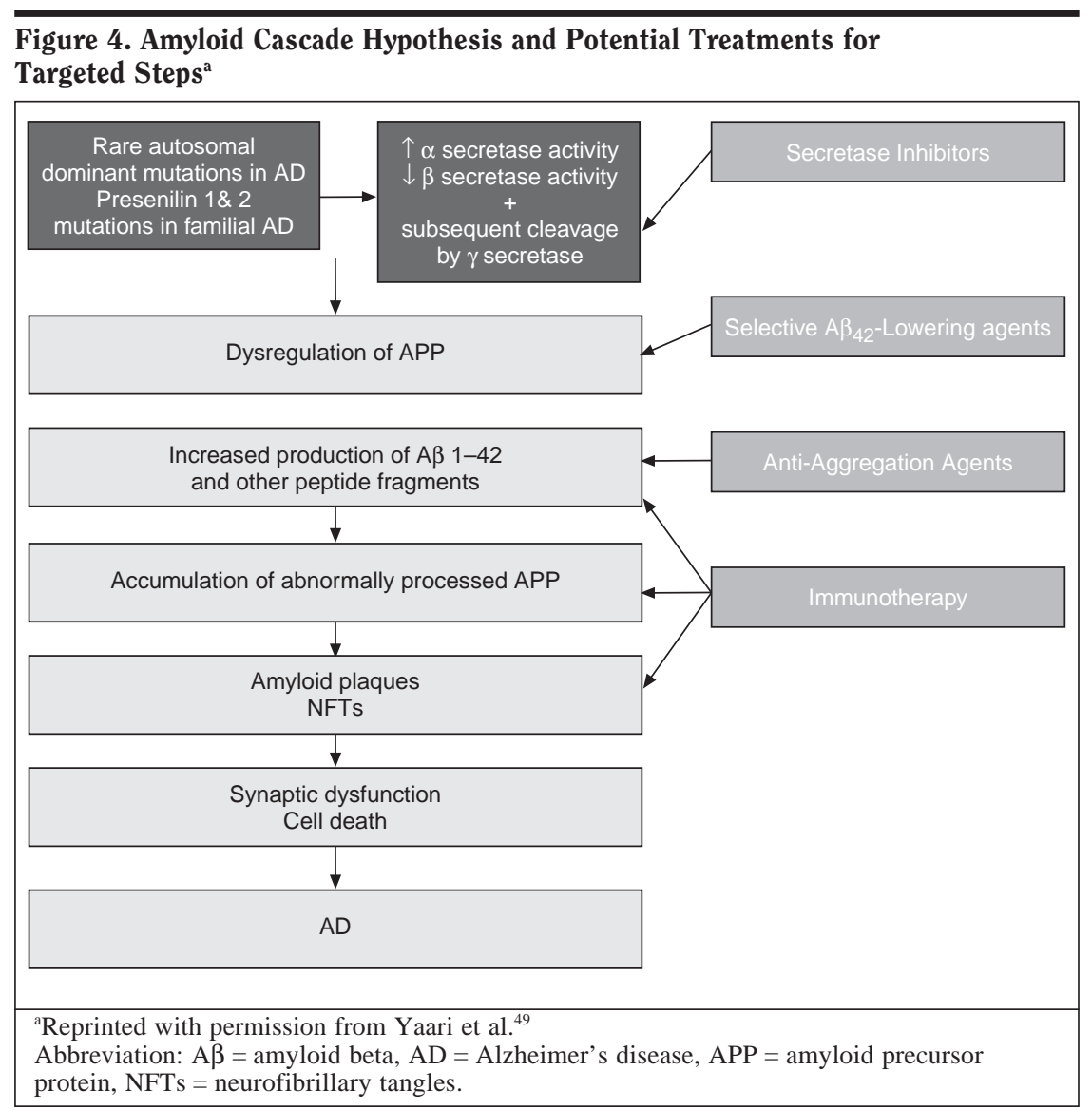

gastrointestinal tract and immune system. ${ }^{61}$ Therefore, current research aims at finding compounds that are specific to the $\gamma$-secretase cleavage of APP. Trials of $\gamma$-secretase inhibitors have demonstrated reduced $\mathrm{A} \beta$ concentration in plasma but not $\mathrm{CSF}^{62}$

Selective $A \beta_{42}$-Lowering Agents. Selective $A \beta_{42}$-lowering agents (SALAs) are NSAID analogues that allosterically modulate, instead of inhibit, $\gamma$-secretase. By altering the site of action of $\gamma$-secretase on the APP membrane (see Figure 4), SALAs promote formation of the shorter, less toxic $A \beta$ peptides and reduce the amount of longer, more toxic $A \beta_{42}$ peptides. ${ }^{63}$ These agents do not seem to affect the Notch system. ${ }^{61}$ One of these agents reached Phase III study but failed to show efficacy on the primary outcome measures, so development stopped. ${ }^{64}$

Anti-aggregation agents. By binding to soluble $A \beta$ peptides, anti- aggregation agents can prevent the downstream toxic effects of $A \beta$ deposition (see Figure 4). A Phase II study ${ }^{65}$ among patients with mild to moderate $\mathrm{AD}$ showed that an anti-aggregation agent reduced CSF A $\beta_{42}$ levels, but test results showed no significant change in cognition. A multicenter Phase III trial failed to show efficacy for cognitive improvement. ${ }^{66}$ Another antiaggregate is in Phase I study. ${ }^{67}$

Heavy metal ions are thought to play a role in the fibrillization of $A \beta$, and a heavy metal chelator could potentially reduce the polymerization of the $A \beta$. One agent with copper and zinc chelation properties reduced plasma $A \beta$ but showed no clinical benefit and was associated with optic nerve damage, so development was halted. ${ }^{68,69}$ A Phase IIa study of another chelating agent showed reduced CSF (but not plasma) $\mathrm{A} \beta_{42}$ concentration and also demonstrated cognitive improvement. ${ }^{70}$
Curcumin, an active ingredient in turmeric powder (giving the spice its color but not flavor), possesses antioxidant and anti-aggregation properties. Curcumin has been shown to bind to amyloid deposits in mice, reducing amyloid plaque burden and reversing some of the structural changes associated with the plaques. ${ }^{71}$ A 6-month pilot clinical trial ${ }^{72}$ did not show clinical benefit, but any protective effect of the agent may have been obscured because patients taking placebo did not show cognitive decline. Finally, colostrinin, a proline-rich polypeptide found in sheep colostrum, is thought to inhibit $\mathrm{A} \beta$ aggregation and has shown a stabilizing effect on cognitive function. ${ }^{73}$

Other amyloid-based interventions. The receptor for advanced glycation endproducts (RAGE) enzyme is a transporter of $A \beta$ from the periphery into the CNS. Inhibition of RAGE is being investigated as a means of blocking the transport of $A \beta$ from the blood to the brain to lower $A \beta$ levels in the $\mathrm{CNS}^{74} \mathrm{~A}$ Phase II trial is underway. ${ }^{75}$

Epidemiologic data ${ }^{76}$ suggest that statins may decrease the risk of dementia, possibly by upregulating $\alpha$ secretase and thereby decreasing toxic $\mathrm{A} \beta_{42}$. Epidemiologic data ${ }^{77}$ have also suggested a reduced risk of dementia, particularly $\mathrm{AD}$, with fish consumption. Docosahexaenoic acid, better known as DHA, is an omega-3 fatty acid found in fish oil and is an integral component of neural membrane phospholipids. A large multicenter Phase III study of DHA for $\mathrm{AD}$ is being conducted. ${ }^{78}$

Tau-based interventions. The abnormal hyperphosphorylation of tau proteins that results in NFTs is associated with an imbalance in the activity levels of tau kinases and phosphatases. Inhibition of the kinases responsible for tau hyperphosphorylation is being pursued as a treatment strategy for treatment of $\mathrm{AD},{ }^{79}$ but development of tau-based interventions lags far behind that of amyloid-based therapies. Lithium and valproate inhibit a kinase that is involved in 
tau hyperphosphorylation, ${ }^{80}$ and research is beginning to explore the viability of these agents as AD treatment. Methylthioninium chloride is an agent thought to inhibit tau aggregation; ${ }^{81}$ a phase III trial is scheduled for 2009 .

\section{Conclusion}

Meaningful advances in the understanding of AD pathophysiology have occurred, said Dr. Yaari, and these have led to the discovery of multiple targets for the development of drugs that could potentially halt or even prevent the disease. Neurotransmitterbased therapies have been shown to improve cognition; all FDA-approved therapies that are currently available are neurotransmitter-based therapies. Amyloid-based therapies are further along in development than other therapies, although it is still unknown whether they will actually yield clinical benefits. The severity of cognitive impairment is closely related to NFTs, but the antitangle therapy pipeline is not as robust as that of the antiamyloid pathway. Progress has been made, but continuing research is needed to develop disease modifying treatments and prevention methods for $\mathrm{AD}$.

Drug names: donepezil (Aricept and others), galantamine (Razadyne and others), lithium (Eskalith, Lithobid, and others), memantine (Namenda), rivastigmine (Exelon and others), selegiline (Eldepryl, Zelapar, and others), tacrine (Cognex).

Disclosure of off-label usage: The chair has determined that, to the best of his knowledge, human intravenous immunoglobulin, lithium, selegiline, and valproate are not approved by the US Food and Drug Administration for the treatment of dementia and Alzheimer's disease.

\section{REFERENCES}

1. Hebert LE, Scherr PA, Bienias JL, et al. Alzheimer disease in the US population: prevalence estimates using the 2000 census. Arch Neurol. 2003;60:1119-1122.

2. Barker WW, Luis CA, Kashuba A, et al. Relative frequencies of Alzheimer disease, Lewy body, vascular and frontotemporal dementia, and hippocampal sclerosis in the State of Florida Brain Bank. Alzheimer Dis Assoc Disord. 2002;16(4):203-212.

3. Gandy $S$. The role of cerebral amyloid $\beta$ accumulation in common forms of $\mathrm{Alz}$ heimer disease. J Clin Invest. 2005;115(5): 1121-1129.

4. Rowe CC, Ng S, Ackermann U, et al. Imaging beta-amyloid burden in aging and dementia. Neurology. 2007;68(20): 1718-1725.

5. Myers RH, Schaefer EJ, Wilson PW, et al. Apolipoprotein E epsilon4 association with dementia in a population-based study: The Framingham study. Neurology. 1996;46(3) 673-677.

6. Bennett DA, Schneider JA, Wilson RS, et al. Neurofibrillary tangles mediate the association of amyloid load with clinical Alzheimer disease and level of cognitive function. Arch Neurol. 2004;61(3):378-384.

7. Gatz M, Reynolds CA, Fratiglioni L, et al. Role of genes and environments for explaining Alzheimer disease. Arch Gen Psychiatry. 2006;63(2):168-174.

8. Petersen RC. Mild cognitive impairment as a diagnostic entity. J Intern Med. 2004; 256:183-194.

9. American Psychiatric Association. Diagnostic and Statistical Manual of Mental Disorders, Fourth Edition, Text Revision. Washington, DC: American Psychiatric Association; 2000.

10. Petersen RC, Morris JC. Mild cognitive impairment as a clinical entity and treatment target. Arch Neurol. 2005;62: 1160-1163.

11. Petersen R, Roberts R, Knopman D, et al. Prevalence of mild cognitive impairment in a population-based study. In: New Research Abstracts of the 59th Annual Meeting of the American Academy of Neurology; Boston, Mass.

12. Petersen RC, Smith GE, Waring SC, et al. Mild cognitive impairment: clinical characterization and outcome. Arch Neurol. 1999:56:303-308.

13. Riemenschneider M, Lautenschlager N, Wagenpfeil S, et al. Cerebrospinal fluid tau and beta-amyloid 42 proteins identify Alzheimer disease in subjects with mild cognitive impairment. Arch Neurol. 2002;59 (11):1729-1734

14. Fagan AM, Roe CM, Xiong C, et al. Cerebrospinal fluid tau/beta-amyloid(42) ratio as a prediction of cognitive decline in nondemented older adults. Arch Neurol. 2007. 64(3):343-349.

15. Graff-Radford NR, Crook JE, Lucas J, et al. Association of low plasma Abeta42/ Abeta40 ratios with increased imminent risk for mild cognitive impairment and Alzheimer disease. Arch Neurol. 2007; 64 (3):354-362.

16. van Oijen M, Hofman A, Soares HD, et al. Plasma Abeta(1-40) and Abeta(1-42) and the risk of dementia: a prospective casecohort study. Lancet Neurol. 2006;5(8): 655-660.

17. Sun X, Steffens DC, Au R, et al. Amyloidassociated depression: a prodromal depression of Alzheimer disease? Arch Gen Psychiatry. 65(5):542-550.

18. Ray S, Britschgi M, Herbert C, et al. Classification and prediction of clinical Alzheimer's diagnosis based on plasma signaling proteins. Nat Med. 2007;13(11): 1359-1362.

19. Knopman DS, DeKosky ST, Cummings JL, et al. Practice parameter: diagnosis of dementia (an evidence-based review).
Neurology. 2001;56:1143-1153.

20. Mueller SG, Weiner MW, Thal LJ, et al. Ways toward an early diagnosis in Alzheimer's disease: the Alzheimer's Disease Neuroimaging Initiative (ADNI) Alzheimer's Dement. 2005;1(1):55-66.

21. Frisoni GB, Sabattoli F, Lee AD, et al. In vivo neuropathology of the hippocampal formation in AD: a radial mapping MR-based study. Neuroimage. 2006; 32(1):104-110.

22. Apostolova LG, Steiner CA, Akopyan GG, et al. Three-dimensional gray matter atrophy mapping in mild cognitive impairment and mild Alzheimer disease. Arch Neurol. 2007;64(10):1489-1495.

23. Silverman DH, Small GW, Chang CY, et al. Positron emission tomography in evaluation of dementia: regional brain metabolism and long-term outcome. JAMA. 2001; 286(17):2120-2127.

24. Silverman DH, Cummings JL, Small GW et al. Added clinical benefit of incorporating 2-deoxy-2[18F]fluoro-D-glucose with positron emission tomography into the clinical evaluation of patients with cognitive impairment. Mol Imaging Biol. 2002 ; 4(4):283-293.

25. Mosconi L, Perani D, Sorbi S, et al. MCI conversion to dementia and the APOE genotype: a prediction study with FDGPET. Neurology. 2004;63(12):2332-2340.

26. Small GW, Ercoli LM, Silverman DHS, et al. Cerebral metabolic and cognitive decline in persons at genetic risk for Alzheimer's disease. Proc Natl Acad Sci U S A. 2000;97(11):6037-6042.

27. Klunk WE, Engler H, Nordberg A, et al. Imaging brain amyloid in Alzheimer's disease with Pittsburgh Compound-B. Ann Neurol. 2004;55(3):306-319.

28. Small GW, Kepe V, Ercoli LM, et al. PET of brain amyloid and tau in mild cognitive impairment. N Engl J Med. 2006;355(25): 2652-2663.

29. Kepe V, Barrio JR, Huang SC. Serotonin $1 \mathrm{~A}$ receptors in the living brain of Alzheimer's disease patients. Proc Natl Acad Sci U S A. 2006;103(3):702-707.

30. Bigler ED, Lowry CM, Kerr D, et al. Role of white matter lesions, cerebral atrophy, and APOE on cognition in older persons with and without dementia: the Cache County, Utah, study of memory and aging. Neuropsychology. 2003;17(3):339-352.

31. Sano M. Neuropsychological testing in the diagnosis of dementia. J Geriatr Psychiatry Neurol. 2006;19(3):155-159.

32. Doniger GM, Dqolatzky T, Zucker DM, et al. Computerized cognitive testing battery identifies mild cognitive impairment and mild dementia even in the presence of depressive symptoms. Am J Alzheimers Dis Other Demen. 2006; 21(1):28-36.

33. Rabins PV, Blacker D, Rovner BW, et al. American Psychiatric Association practice guideline for the treatment of patients with Alzheimer's disease and other dementias, second edition. Am J Psychiatry. 2007; 164(suppl 12): 5-55.

34. Lyketsos CG, Colenda CC, Beck C, et al for the Task Force of American Association for Geriatric Psychiatry. Position statement of the American Association for Geriatric Psychiatry regarding principles of care for patients with dementia resulting from Alzheimer disease. 
Am J Geriatr Psychiatry. 2006;14(7): 561-572.

35. Doody RS, Stevens JC, Beck C, et al. Practice parameter: management of dementia (an evidence-based review). Report of the Quality Standards Subcommittee of the American Academy of Neurology. Neurology. 2001;56(9):1154-1166

36. Geldmacher DS. Treatment guidelines for Alzheimer's disease: redefining perceptions in primary care. Prim Care Companion J Clin Psychiatry. 2007;9(2):113-121.

37. Cummings JL, Doody R, Clark C. Diseasemodifying therapies for Alzheimer disease: challenges to early intervention. Neurology. 2007;69(16):1622-1634.

38. Bartus RT, Dean RL, Beer B3, et al. The cholinergic hypothesis of geriatric memory dysfunction. Science. 1982;217(4558): 408-414.

39. Whitehouse PJ, Price DL, Struble RG, et al. Alzheimer's disease and senile dementia: loss of neurons in the basal forebrain. Science. 1982;215(4537):1237-1239.

40. Nordberg A. Nicotinic receptor abnormalities of Alzheimer's disease: therapeutic implications. Biol Psychiatry. 2001;49(3): 200-210.

41. Newhouse PA, Potter A, Kelton M, et al. Nicotinic treatment of Alzheimer's disease. Biol Psychiatry. 2001;49:268-278.

42. Mattson MP, Pedersen WA, Duan W, et al. Cellular and molecular mechanisms underlying perturbed energy metabolism and neuronal degeneration in Alzheimer's and Parkinson's diseases. Ann N Y Acad Sci. 1999;893:154-175.

43. Rothman SM, Thurston JH, Hauhart RE. Delayed neurotoxicity of excitatory amino acids in vitro. Neuroscience. 1987;22(2): 471-480.

44. Panula P, Rinne J, Kuokkanen K, et al. Neuronal histamine deficit in Alzheimer's disease. Neuroscience. 1998;82(4): 993-997.

45. Witkin JM, Nelson DL. Selective histamine $\mathrm{H} 3$ receptor antagonists for treatment of cognitive deficiencies and other disorders of the central nervous system. Pharmacol Ther. 2004;103(1):1-20.

46. Doody RS, Gavrilova SI, Sano M, et al. Effect of dimebon on cognition, activities of daily living, behaviour, and global function in patients with mild-to-moderateAlzheimer's disease: a randomized, double-blind, placebo-controlled study. Lancet. 2008;372(9634):207-215.

47. Bachurin SO, Shevtsova EP, Kireeva EG, et al. Mitochondria as a target for neurotoxins and neuroprotective agents. Ann N Y Acad Sci. 2003;993:334-349.

48. Bachurin S, Bukatina E, Lermontova N, et al. Antihistamine agent Dimebon as a novel neuroprotector and a cognition enhancer. Ann N Y Acad Sci. 2001;939:425-435.

49. Yaari R, Kumar S, Tariot PN. Noncholinergic drug development for Alzheimer's disease. Expert Opinion. 2008;3(7):745-760.

50. Gelinas DS, DaSilva K, Fenili D, et al. Immunotherapy for Alzheimer's disease. Proc Natl Acad Sci U S A. 2004; 101(Suppl 2):14657-14662.

51. Matsuoka Y, Saito M, LaFrancois J, et al.
Novel therapeutic approach for the treatment of Alzheimer's disease by peripheral administration of agents with an affinity to betaamyloid. J Neurosci. 2003;23(1):29-33.

52. Schenk D, Barbour R, Dunn W, et al. Immunization with amyloid- $\beta$ attenuates Alzheimer-disease-like pathology in the PDAPP mouse [letter]. Nature. 1999; 400(6740): 173-177.

53. Kotilinek LA, Bacskai B, Westerman M, et al. Reversible memory loss in a mouse transgenic model of Alzheimer's disease. J Neurosci. 2002;22(15):6331-6335.

54. Gilman S, Koller M, Black RS, et al. Clinical effects of Abeta immunizations (AN1792) in patients with AD in an interrupted trial. Neurology. 2005;64(9): 1553-1562.

55. Fox NC, Black RS, Gilman S, et al. Effects of Abeta immunization (AN1792) on MRI measures of cerebral volume in Alzheimer disease. Neurology. 2005;64(9):1563-1572.

56. Nicoll JA, Barton E, Boche D, et al. Abeta species removal after abeta42 immunization. J Neuropathol Exp Neurol. 2006;65(11): 1040-1048.

57. Bales KR, Tzavara ET, Wu S, et al. Cholinergic dysfunction in a mouse model of Alzheimer disease is reversed by an anti-A beta antibody. J Clin Invest. 2006;116(3): 825-832.

58. Elan Corporation, plc. Elan and Wyeth announce encouraging top-line results from phase 2 clinical trial of bapineuzumab for Alzheimer's disease. 2008. Available at http://www.elan.com/news/ full.asp?ID=1166655. Accessed Jan 7, 2009.

59. Dodel RC, Du Y, Depboylu C, et al. Intravenous immunoglobulins containing antibodies against beta-amyloid for the treatment of Alzheimer's disease. J Neurol Neurosurg Psychiatry. 2004;75(10):1472-1474.

60. Relkin NR, Szabo P, Adamiak B, et al. 18-Month study of intravenous immunoglobulin for treatment of mild Alzheimer disease. [published online ahead of print February 20, 2008]. Neurobiol Aging.

61. Evin G, Sernee MF, Maters CL. Inhibition of gamma-secretase as a therapeutic intervention for Alzheimer's disease: prospects, limitations and strategies. CNS Drugs. 2006;20(5):351-372.

62. Fleisher AS, Raman R, Siemers ER, et al. Phase 2 safety trial targeting amyloid beta production with a gamma-secretase inhibitor in Alzheimer disease. Arch Neurol. 2008; 65(8):1031-1038

63. Beher D, Clarke EE, Wrigley JD, et al. Selected non-steroidal anti-inflammatory drugs and their derivatives target gamma-secretase at a novel site: evidence for an allosteric mechanism. J Biol Chem. 2004;279(42): 43419-43426.

64. Myriad Genetics. Myriad Genetics reports results of U.S. Phase 3 trial of Flurizan in Alzheimer's disease. 2008. Available at http://www.myriad.com/news/release/ 1170283. Accessed Nov 3, 2008.

65. Aisen PS, Saumier D, Briand R, et al. A Phase II study targeting amyloid-beta with 3APS in mild-to-moderate Alzheimer disease. Neurology. 2006;67(10):1757-1763.

66. Alzheimer Research Forum. Drugs in clinical trials. 2008
Available at http://www.alzforum.org/drg/ drc/detail.asp?id=84. Accessed Nov 6, 2008.

67. Transition Therapeutics Inc. Transition Therapeutics reports results from Canadian Phase I clinical trial of Alzheimer's disease drug product AZD-103. 2006. Available at http://www.transitiontherapeutics.com/news/ article.php. Accessed 2008.

68. Ritchie CW, Bush AI, Mackinnon A, et al. Metal-protein attenuation with iodochlorhydroxyquin (clioquinol) targeting Abeta amyloid deposition and toxicity in Alzheimer disease; a pilot phase 2 clinical trial. Arch Neurol. 2003;60(12):1685-1691.

69. Tateishi J. Subacute myelo-opticoneuropathy: clioquinol intoxication in humans and animals. Neuropathology. 2000;20(Suppl):S20-24

70. Lannfelt L, Blennow K, Zetterberg H, et al. Safety, efficacy, and biomarker findings of PBT2 in targeting Abeta as a modifying therapy for Alzheimer's disease: a phase IIa, double-blind, randomised, placebocontrolled trial. Lancet Neurol. 2008; 7(9):779-786.

71. Garcia-Alloza M, Borrelli LA, Rozkaine A, et al. Curcumin labels amyloid pathology in vivo, disrupts existing plaques, and partially restores distorted neurites in an Alzheimer mouse model. J Neurochem. 2007;102(4): 1095-1104.

72. Baum L, Lam CW, Cheung SK, et al. Six-month randomized, placebo-controlled, double-blind, pilot clinical trial of curcumin in patients with Alzheimer disease. J Clin Psychopharmacol. 2008;28(1):110-113.

73. Bilikiewicz A, Gaus W. Colostrinin (a naturally occurring, proline-rich, polypeptide mixture) in the treatment of Alzheimer's disease. J Alzheimers Dis. 2004;6(1):17-26.

74. Zlokovic BV. Clearing amyloid through the blood-brain barrier. J Neurochem. 2004; 89(4):807-811.

75. Pfizer Inc. A Phase 2 study evaluating the efficacy and safety of PF 04494700 in mild to moderate Alzheimer's disease. 2008. Available at http://www.clinicaltrials.gov/ ct2/show/NCT00566397?term=RAGE+ inhibitor+dementia\&rank $=1$. Accessed Dec 2, 2008.

76. Jick H, Zornberg GL, Jick SS, et al. Statins and the risk of dementia. Lancet. 2000; 356(9242):1627-1631.

77. Kalmijn S, Launer LJ, Ott A, et al. Dietary fat intake and the risk of incident dementia in the Rotterdam Study. Ann Neurol. 1997; 42(5):776-782.

78. DHA (docosahexaenoic acid), an omega 3 fatty acid, in slowing the progression of Alzheimer's disease. 2007. Available at http:// www.clinicaltrials.gov/ct/show/ NCT00440050. Accessed Nov 11, 2008.

79. Churcher I. Tau therapeutic strategies for the treatment of Alzheimer's disease. Curr Top Med Chem. 2006;6(6):579-595.

80. Kim AJ, Shi Y, Austin RC, et al. Valproate protects cells from ER stress-induced lipid accumulation and apoptosis by inhibiting glycogen synthase kinase-3. J Cell Sci. 2005;118(Pt 1):89-99.

81. TauRx Therapeutics Ltd. PipelineAlzheimer's disease. 2008. Available at http://www.taurx.com/pipeline_first.aspx. Accessed Jan 7, 2009.

For the CME Posttest for this Academic Highlights, see pages 302-304. 